\title{
KIDNEY INJURY MOLECULE-1 AS AN EARLY AMIKACIN-INDUCED NEPHROTOXICITY MARKER IN PATIENTS WITH SEPSIS HOSPITALIZED IN THE INTENSIVE CARE UNIT
}

\section{TRISNI UNTARI DEWI, INSTIATY, RUDIANTO SEDONO, GESTINA ALISKA, MUHAMMAD KHIFZHON AZWAR, RIANTO SETIABUDY*}

\author{
Department of Pharmacology and Therapeutic, Faculty of Medicine, Universitas Indonesia, Jakarta. Email: rianto_set@yahoo.com
}

Received: 30 September 2018, Revised and Accepted: 13 March 2019

\begin{abstract}
Objective: This study sought to determine the correlation between trough plasma amikacin concentrations and urinary normalized kidney injury molecule-1 (KIM-1) concentrations as an early biomarker of nephrotoxicity in patients with sepsis who are hospitalized in an intensive care unit.
\end{abstract}

Methods: In this pilot study, 12 patients with sepsis were treated with amikacin $1000 \mathrm{mg} /$ day between May 2015 and September 2015. The correlation between trough plasma amikacin concentrations measured after the third dose and the elevation of urinary normalized KIM-1 concentrations after the third amikacin dose relative to the first/second dose was evaluated.

Results: In total, three patients had trough plasma amikacin concentrations exceeding the safe level ( $>10 \mu \mathrm{g} / \mathrm{ml}$ ). Furthermore, eight patients displayed higher normalized KIM-1 concentrations after third dose than after the first/second dose; however, there was no correlation between trough amikacin concentrations and the elevation of urinary normalized KIM-1 concentrations ( $r=0.3, p=0.3)$.

Conclusion: The study results illustrated that short-term treatment with an amikacin dose of $1000 \mathrm{mg} /$ day was generally safe in patients with sepsis.

Keywords: Amikacin, Kidney injury molecule-1, Nephrotoxicity

(c) 2019 The Authors. Published by Innovare Academic Sciences Pvt Ltd. This is an open access article under the CC BY license (http://creativecommons. org/licenses/by/4. 0/) DOI: http://dx.doi.org/10.22159/ijap.2019.v11s1.031

\section{INTRODUCTION}

Sepsis is a common cause of mortality, and severe sepsis results in death in up to $50 \%$ of patients [1]. Aminoglycosides, especially amikacin, are the most commonly used antibiotics in patients with sepsis due to Gram-negative bacterial infections even though these drugs can induce nephrotoxicity in $10-20 \%$ of patients [2].

Amikacin has a different structure than other aminoglycosides; therefore, it is not inactivated by enzymes that commonly inactivate gentamicin [2]. An adequate plasma level of amikacin is needed to kill the bacteria that cause sepsis. The target amikacin concentration for treating bacterial sepsis is $20-40 \mu \mathrm{g} / \mathrm{ml}$, whereas the trough level to avoid nephrotoxicity is less than $10 \mu \mathrm{g} / \mathrm{ml}[3,4]$.

Acute kidney injury (AKI) is traditionally diagnosed by measuring blood urea nitrogen and serum creatinine levels; however, these parameters are neither sensitive nor specific for establishing a diagnosis of AKI. A more specific AKI biomarker is kidney injury molecule-1 (KIM-1) [5]. KIM-1 is a tubular protein that is induced by ischemic reperfusion injury or exposure to proximal tubule toxins. KIM-1 can be produced at the site of injury, and it can be measured quantitatively, rapidly, and easily in urine or blood [6].

Currently, the dose of amikacin used in the intensive care unit (ICU) of Cipto Mangunkusumo Hospital (RSCM) is $1000 \mathrm{mg} /$ day, compared to a recommended dose of $15 \mathrm{mg} / \mathrm{kg} \mathrm{BW}[7,8]$. It is unknown whether the currently used dose would generate a trough amikacin level exceeding the minimum level known to cause nephrotoxicity. This study examined trough plasma amikacin levels in patients with sepsis hospitalized in the ICU of RSCM who were treated with amikacin $1000 \mathrm{mg} /$ day, and the relationship between trough amikacin and urinary KIM-1 levels was analyzed.

\section{METHODS}

Trough plasma amikacin levels and urinary normalized KIM-1 levels were measured in patients with sepsis who received amikacin
$1000 \mathrm{mg} /$ day in the ICU of RSCM. All patients in this study had good renal function. Trough plasma amikacin levels were measured after the third dose (immediately before the fourth dose was administered), whereas urinary normalized KIM-1 levels were measured after the first/second and third doses. The correlations of the difference of normalized KIM-1 levels between the first/second and third doses and the third-dose trough amikacin levels were evaluated.

Blood samples were obtained from patients 5 min before the fourth dose of amikacin was administered to measure trough amikacin levels. Plasma samples were transferred to the pharmacokinetics laboratory after centrifugation and stored at $-20^{\circ} \mathrm{C}$ before analysis. Plasma amikacin levels were measured through liquid chromatography-tandem mass spectrometry using a Waters Alliance 2695 high-performance liquid chromatography system and Quatro Micro Triple Quadrupole MS detector with the lowest limit of quantification of $1 \mu \mathrm{g} / \mathrm{ml}$. To measure absolute urinary KIM-1 levels, $1 \mathrm{ml}$ of a 24 -h urine sample (starting immediately after administration of the first or second dose of amikacin until immediately before the next dose) was used. The urinary samples were analyzed through enzyme-linked immunosorbent assay using a KIM-1 kit (R and D Systems DKM 100). The remainder of the urinary samples was transported to the clinical pathology laboratory of RSCM to quantify urine creatinine levels.

The correlation between trough plasma amikacin levels and the increase of normalized KIM-1 levels was verified using Spearman's test. The differences between the first-/second-dose and third-dose urinary normalized KIM-1 levels were analyzed using Wilcoxon's test.

\section{RESULTS}

Subject selection was performed from May 2015 to September 2015. Among 20 targeted patients, only 15 could be recruited. Of these subjects, one died before the sample for trough amikacin and third-dose KIM-1 level measurements were obtained. A second subject could not provide 
the day 3 urinary creatinine measurement sample. Another subject was excluded due to prior continuous renal replacement therapy. Thus, data were analyzed for 12 subjects. The basic characteristics of the subjects are shown in Table 1.

The administration of amikacin $1000 \mathrm{mg} /$ day resulted in varied trough amikacin levels after the third dose (Table 2). In total, three subjects had trough levels exceeding $10 \mu \mathrm{g} / \mathrm{ml}$.

In this study, 8/12 subjects (66.7\%) exhibited elevated normalized urinary KIM-1 levels after the third dose compared to those after the first or second dose.

The Spearman correlation test revealed no correlation between trough amikacin levels and changes of urinary KIM-1 levels among the 12 subjects $(\mathrm{r}=0.3, \mathrm{p}=0.3)$. Meanwhile, patient 7 was excluded from Pearson's correlation test because this patient's trough amikacin level differed by $>2$ standard deviation from the median trough level of the subjects. However, the result also revealed no correlation between trough amikacin levels after the third dose and the difference of the

Table 1: Basic characteristics of the subjects

\begin{tabular}{ll}
\hline Characteristics & Number of subjects (\%) \\
\hline Sex & \\
$\quad$ Male & $5(41.7)$ \\
Female & $7(58.3)$ \\
Age & \\
18-65 years & $12(100)$ \\
Creatinine clearance $(\mathrm{ml} / \mathrm{min})$ & \\
$60-90$ & $2(16.7)$ \\
$>90$ & $10(83.3)$ \\
Total & $12(100)$ \\
\hline
\end{tabular}

Table 2: Trough level plasma of amikacin

\begin{tabular}{lll}
\hline No & Patient & $\mathbf{C}_{\min }(\mu \mathrm{g} / \mathbf{m l})$ \\
\hline 1 & Patient 1 & 1.26 \\
2 & Patient 2 & 4.56 \\
3 & Patient 4 & 6.74 \\
4 & Patient 5 & 4.83 \\
5 & Patient 6 & 3.19 \\
6 & Patient 7 & 27.04 \\
7 & Patient 9 & 3.24 \\
8 & Patient 10 & 12.59 \\
9 & Patient 11 & 8.29 \\
10 & Patient 12 & 8.04 \\
11 & Patient 13 & 13.75 \\
12 & Patient 15 & 4.22 \\
\hline
\end{tabular}

Table 3: KIM-1 levels in urin

\begin{tabular}{|c|c|c|c|c|c|c|}
\hline No & Subject & $\begin{array}{l}\text { Absolute KIM-1 level } \\
\text { after the } 1^{\text {st }} \text { or } 2^{\text {nd }} \\
\text { dose }(\mathrm{ng} / \mathrm{ml})\end{array}$ & $\begin{array}{l}\text { Absolute KIM-1 level } \\
\text { after the } 3^{\text {rd }} \text { dose } \\
(\mathrm{ng} / \mathrm{ml})\end{array}$ & $\begin{array}{l}\text { Normalized KIM-1 } \\
\text { level after the } 1^{\text {st }} \text { or } 2^{\text {nd }} \\
\text { dose }(\mu \mathrm{g} / \mathrm{g})\end{array}$ & $\begin{array}{l}\text { Normalized KIM-1 } \\
\text { level after the } 3^{\text {rd }} \\
\text { dose }(\mu \mathrm{g} / \mathrm{g})\end{array}$ & $\begin{array}{l}\text { Difference between the } \\
1^{\text {st }} \text { or } 2^{\text {nd }} \text { dose and } 3^{\text {rd }} \\
\text { dose }(\mu \mathrm{g} / \mathrm{g})^{*}\end{array}$ \\
\hline 1 & Patient 1 & 1.78 & 0.45 & 1.37 & 0.68 & -0.69 \\
\hline 2 & Patient 2 & 1.31 & 1.60 & 1.74 & 3.09 & 1.35 \\
\hline 3 & Patient 4 & 0.23 & 0.04 & 0.39 & 0.20 & -0.19 \\
\hline 4 & Patient 5 & 0.53 & 0.41 & 1.06 & 1.25 & 0.19 \\
\hline 5 & Patient 6 & 0.67 & 0.54 & 1.42 & 1.30 & -0.12 \\
\hline 7 & Patient 9 & 0.80 & 1.48 & 4.74 & 6.22 & 1.48 \\
\hline 8 & Patient 10 & 2.08 & 3.98 & 5.81 & 9.31 & 3.5 \\
\hline 9 & Patient 11 & 5.49 & 3.96 & 23.13 & 18.68 & -4.45 \\
\hline 10 & Patient 12 & 8.56 & 6.15 & 25.22 & 27.72 & 2.5 \\
\hline 11 & Patient 13 & 1.87 & 0.79 & 4.68 & 5.48 & 0.8 \\
\hline 12 & Patient 15 & 9.45 & 6.80 & 17.02 & 17.10 & 0.08 \\
\hline
\end{tabular}

*The third-dose normalized KIM-1 level was subtracted from first- or second-dose normalized KIM-1 level, KIM-1: Kidney injury molecule-1 urinary normalized KIM-1 levels between the third and first/second doses ( $\mathrm{p}=0.478 ; \mathrm{r}=0.24)$.

Eight subjects in this study exhibited higher $3^{\text {rd }}$-day normalized KIM-1 levels compared to the $1^{\text {st }} / 2^{\text {nd }}$-day levels; however, the increase was not KIM-1 levels were also detected among the subjects (Tables 3 and 4).

\section{DISCUSSION}

This study evaluated the correlation between the trough level of amikacin following administration at $1000 \mathrm{mg} /$ day and the increase of normalized KIM-1 levels as a marker of kidney damage in patients with sepsis. The failure to obtain a correlation between the variables could may have reduced the power of the statistical test.

Despite the subjects ranging in weight from 35 to $70 \mathrm{~kg}$, the dose of amikacin is $1000 \mathrm{mg}$ /day for all patients with sepsis in the ICU of RSCM regardless of their weight. Consequently, the trough amikacin level in patient 7 , who had the lowest weight, exceeded the recommended level of $15-25 \mathrm{mg} / \mathrm{kg}[7,8]$. This patient received an amikacin dose of $28.6 \mathrm{mg} / \mathrm{kg}$ BW, leading to elevated trough amikacin and normalized KIM-1 levels. Based on these findings, this patient may have had an increased risk of developing nephrotoxicity [9]

Conversely, patient 12 (90 kg), who had a body mass index (BMI) of 37, exhibited increased normalized KIM-1 levels after the third dose despite a trough amikacin level below the safe threshold. Determination of amikacin dose for obese patients is based on the ideal body weight rather than the actual body weight, using the formula: ideal body weight +0.4 (total body weight- ideal body weight) $\times$ amikacin dose [10] . The elevation of KIM-1 levels may be related to the condition of the patient, who had septic shock. In line with these data, a study by Balqis et al. [11] found that patients with sepsis and AKI have higher absolute KIM-1 levels (median $=2.7 \mathrm{ng} / \mathrm{ml}$, range $=0.7-13.4$ ) than those without AKI (median=0.8 ng/ml, range $=0-3.4, \mathrm{p}<0.001$ ).

Meanwhile, patient 10 had an increased normalized KIM-1 level after the third dose. This patient, who was 60 years old, had a history of AKI that was resolved 2 week before sepsis developed. The risk factors for aminoglycoside-induced nephrotoxicity include age, concurrent disease, hepatic dysfunction, septic condition, and kidney dysfunction [12]. However, of KIM-1 levels with age, sex, and BMI in 79 critically ill patients.

This study had a number of limitations. First, the number of subjects was small and fewer than expected. The sample size required according to the obtained correlation value $(r)$ in this study, as determined using the formula $\{(\mathrm{Z} \alpha+\mathrm{Z} \beta) /(0.5 \ln [1+\mathrm{r}] /[1-\mathrm{r}])\}^{2}+3[14]$, was 51 . statistically significant (Wilcoxon's test, $p=0.19$, Table 3 ). Varied urinary be due to the lower-than-expected number of enrolled subjects. This a study performed by Boghdady et al. [13] identified no association 
Table 4: Urinary KIM-1 levels

\begin{tabular}{|c|c|c|c|}
\hline \multirow[t]{2}{*}{ KIM-1 category } & \multicolumn{2}{|c|}{ KIM-1 level } & \multirow{2}{*}{$\begin{array}{l}\text { Total number } \\
\text { of subjects }\end{array}$} \\
\hline & Median & Range & \\
\hline Absolute KIM-1 level after the first or second dose (ng/ml) & 1.54 & $0.23-9.45$ & 12 \\
\hline Normalized KIM-1 level after the first or second dose $(\mu \mathrm{g} / \mathrm{g})$ & 3.82 & $0.39-25.22$ & 12 \\
\hline Normalized KIM-1 level after the third dose $(\mu \mathrm{g} / \mathrm{g})$ & 4.58 & $0.2-27.72$ & 12 \\
\hline Difference in normalized KIM-1 levels between the first or second dose and the third dose $(\mu \mathrm{g} / \mathrm{g})^{*}$ & 0.45 & $-4.45-3.5$ & 12 \\
\hline Total number of subjects & & & 12 \\
\hline
\end{tabular}

*The third-dose normalized KIM-1 level was subtracted from first- or second-dose normalized KIM-1 level, KIM-1: Kidney injury molecule-1

Another limitation was that the initial KIM-1 level before amikacin administration was not measured due to difficulties in finding eligible patients for this study. The initial level was needed to obtain information about the kidney function of the patients before therapy and ensure the absence of other factors affecting nephrotoxicity risk. In addition, KIM-1 levels were not compared between the patients and healthy controls.

\section{CONCLUSION}

In this study, no correlation was found between the trough amikacin levels and the elevation of urinary normalized KIM-1 levels after the third amikacin dose. After 3 days of treatment with $1000 \mathrm{mg} /$ day amikacin, the trough levels of the drug in patients with sepsis were generally within the safe limits for avoiding nephrotoxicity $(<10 \mu \mathrm{g} / \mathrm{ml})$.

\section{CONFLICTS OF INTEREST}

The authors have no conflicts of interest to be declared.

\section{REFERENCES}

1. Mahmoudi L, Mohammadpour AH, Ahmadi A, Niknam R, Mojtaheddzadeh M. Influence of sepsis on higher daily dose of amikacin pharmacokineticsincriticallyillpatients.EurRevMedPharmacolSci2013; 17:285-91.

2. Martínez-Salgado C, López-Hernández FJ, López-Novoa JM. Glomerular nephrotoxicity of aminoglycosides. Toxicol Appl Pharmacol 2007;223:86-98.

3. Setiabudy R, Suwento R, Rundjan L, Yasin FH, Louisa M, Dwijayanti A, et al. Lack of a relationship between the serum concentration of aminoglycosides and ototoxicity in neonates. Int J Clin Pharmacol Ther 2013;51:401-6.
4. Deck DH, Winston LG. Aminoglycosides and spectinomycin. In: Katzung BG, Masters SB, Trevor AJ, editors. Basic and Clinical Pharmacology. $12^{\text {th }}$ ed. Singapore: McGraw-Hill; 2012. p. 821-7.

5. Bonventre JV. Kidney injury molecule-1 (KIM-1): A urinary biomarker and much more. Nephrol Dial Transplant 2009;24:3265-8.

6. Chaturvedi S, Farmer T, Kapke GF. Assay validation for KIM-1: Human urinary renal dysfunction biomarker. Int J Biol Sci 2009;5:128-34.

7. Taccone FS, Laterre P, Herbert SH, Dugernier T, Delattre I, Layeux B, et al. Revisiting the loading dose of amikacin for patients with severe sepsis and septic shock. Crit Care 2010;14:R53.

8. Petri WA. Aminoglycosides. In: Hardman JG, Limbird LE, editors. Goodman and Gilman's the Pharmacological Basis of Therapeutics. $12^{\text {th }}$ ed. New York: McGraw-Hill; 2011. p. 1516-7.

9. Beaucaire G. Does once-daily dosing prevent nephrotoxicity in all aminoglycosides equally? Clin Microbiol Infect 2000;6:357-62.

10. Pai MP, Bearden DT. Antimicrobial dosing considerations in obese adult patients: Insights from the society of infectious diseases pharmacists. Pharmacotherapy 2007;27:1081-91.

11. Balqis LF, Noormartany, Gondodiputro RS, Rita C. Validity of kidney injury molecule-1 urin metode mikro enzyme-linked immunosorbent assay as a early prevention for acute kidney disorders in sepsis. Majalah Kedokt Bandung 2016;48:19-25.

12. Oliveira JF, Silva CA, Barbieri CD, Oliveira GM, Zanetta DM, Burdmann EA. Prevalence and risk factor for aminoglycoside nephrotoxicityinintensivecareunits.AntimicrobAgentsChemother2009; 53:2887-91

13. Boghdady IM, Naggara MM, Emaraa MM, El-Shazlyb RM, Mahmouda KS. Kidney injury molecule-1 as an early marker for acute kidney injury in critically ill patients. Menoufia Med J 2013;26:98-104.

14. Dahlan MS. Using the sample size formula correctly. In: Large Edition Sample and Sampling Method in Medical and Health Research. Jakarta: Salemba Medika; 2010. p. 76-7. 